\title{
Protective effects of some anionic surfactants on an Ag-containing aluminium alloy (AA2139). Comparison with the action on a Li-containing aluminium alloy (AA2198)
}

\author{
A. Frignani,* A. Balbo, V. Grassi and F. Zucchi \\ Corrosion and Metallurgy Study Centre “A. Daccò”, Engineering Department, University \\ of Ferrara, v. G. Saragat 4a, 44122, Ferrara (I). \\ *E-mail: a.frignani@unife.it
}

\begin{abstract}
The influence exerted by some anionic surfactants towards the corrosion process of an Agcontaining aluminium alloy (AA2139) is studied during $168 \mathrm{~h}$ immersion in $0.01 \mathrm{M} \mathrm{NaCl}$ solution. This behaviour is compared with that previously determined on a Li-containing alloy (AA2198). The surfactants, at a proper concentration, hinder anodic and cathodic reactions as well as the pitting process, but their action is influenced by passive layer stability, so that their inhibiting effects are greater on AA2198 for the more efficient and stable passive layer. On both alloys, the most efficient compounds are the sodium salts of N-lauroylsarcosine and of dodecylbenzensulphonic acid.
\end{abstract}

Key words: aluminium, anionic surfactant, corrosion, inhibition, pitting.

Received: April 4, 2013.

doi: $10.17675 / 2305-6894-2013-2-2-138-149$

\section{Introduction}

In aqueous media the corrosion rate of aluminium alloys is usually reduced by the formation of a layer of spontaneous corrosion products (Al oxide-hydroxide passivating layer). The passive current density and the potential extension of the passive zone depends on the alloy composition, environmental composition and $\mathrm{pH}$, and temperature. However, stable passivity is markedly impaired by particular anions, for instance, nitrates and chiefly chlorides [1,2], which reduce the passive interval and increase the anodic currents. Furthermore, the presence of cathodic intermetallic phases can lead to localized attacks.

In recent aluminium alloys, the presence of novel types of intermetallics with new characteristics can greatly affect the alloy corrosion performances and influence the effects of the anions towards their passive behaviour.

To contrast chloride attack, among the organic substances [3-13], anionic surfactants $[4,6]$ were also experimented, since their long aliphatic chain should allow the formation of a compact and hydrophobic layer while their negative polar head, in addition to allowing the anchoring onto the aluminium oxide layer, should efficaciously withstand chloride anion action.

The present research studies the influence exerted by some anionic surfactants (chiefly sodium salt of N-lauroylsarcosine, NLS, and of dodecylbenzensulphonic acid, 
DBS) towards the corrosion attack of an Ag-containing aluminium alloy (AA2139) during $168 \mathrm{~h}$ immersion in $0.01 \mathrm{M}$ sodium chloride solution, and then compares these effects with those previously found on a Li-containing AA2138 alloy in the same environment, since it was seen that the action of an inhibiting substance can also depend on aluminium alloy composition [14]. It was previously revealed that the action of NLS and DBS were very effective both on AA6531 Si-containing aluminium alloy [6] and AA2198 Li-containing aluminium alloy [15]. In the former paper NLS was found to act through chemical adsorption on the aluminium oxide layer, while DBS and the other surfactants through a physical adsorption, and this different mode of interaction accounted for the enhanced performances of NLS. In the latter paper the different efficiency of the two additives was confirmed, highlighting their particularly strong effects on the alloy pitting process.

\section{Experimental}

Square specimens (around $1.25 \times 1.25 \mathrm{~cm}$ ) were obtained from a $0.5 \mathrm{~cm}$ thick plate of T3 treated AA2139 alloy and from a laminated, T3 treated, AA2198 alloy, whose percent by weight chemical compositions (EDS analysis) are reported in Table 1.

Table 1. Chemical percent (in weight) composition of aluminium alloys (EDS analysis).

\begin{tabular}{ccccccccc}
\hline & Alloy & \multicolumn{7}{c}{ Composition (wt\%) } \\
\cline { 2 - 9 } & & $\mathbf{F e}$ & $\mathbf{C u}$ & $\mathbf{M n}$ & $\mathbf{A g}$ & $\mathbf{M g}$ & $\mathbf{Z r}$ & $\mathbf{L i}$ \\
\hline \multirow{2}{*}{ AA2139 T3 } & $\begin{array}{c}\text { Base } \\
\text { Material }\end{array}$ & 0.09 & 4.52 & 0.29 & 1.57 & 0.34 & n.d. & 0 \\
\cline { 2 - 9 } & Intermetallics & 5.30 & 20.04 & 1.80 & 0.61 & 0.24 & n.d. & 0 \\
\hline $\begin{array}{c}\text { AA2198 } \\
\text { T3 } \\
\text { laminated }\end{array}$ & $\begin{array}{c}\text { Base } \\
\text { Material }\end{array}$ & 0.10 & 3.34 & n.d. & 1.16 & 0.35 & 0.18 & 1 \\
\cline { 2 - 9 } & Intermetallics & 6.91 & 19.39 & n.d. & 0.31 & 0.26 & 0.13 & n.d. \\
\hline
\end{tabular}

$*_{\text {n.d. }}=$ not determined

The structure of AA2139 was formed by equiaxial grains, while that of AA2198 by fine elongated grains (due to the lamination process, Figures 1a,c). Both AA2139 (Agcontaining aluminium alloy) and AA2198 (Li-containing aluminium alloy) were characterized by the presence of $\mathrm{Cu}-(\mathrm{Mn}-)$ and Fe-rich intermetallic precipitates (Figures $1 \mathrm{~b}$,d; Table 1); in former alloy these precipitates were more numerous while in the latter alloy were aligned along the lamination direction.

Figures 2 ( $a$ and $b$ ) show the appearances of AA2139 and AA2198 surfaces after $4 \mathrm{~h}$ immersion in $0.6 \mathrm{M} \mathrm{NaCl}$ solution: the points of attack on AA2139 were more numerous than on AA2198. It was found (Figure 2c) that, as usual [16, 17], the corrosion attack started in the $\mathrm{Cu}$-depleted zones adjacent the cathodic $\mathrm{Cu}$ - and $\mathrm{Fe}$-rich precipitates. 


\section{AA2139}
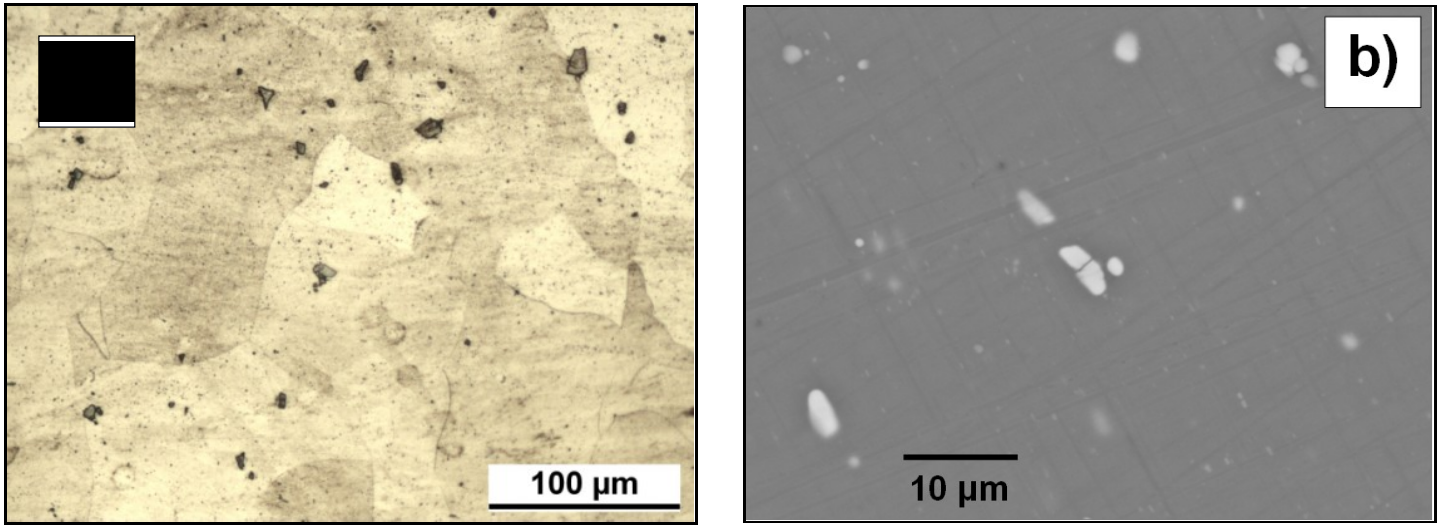

AA2198
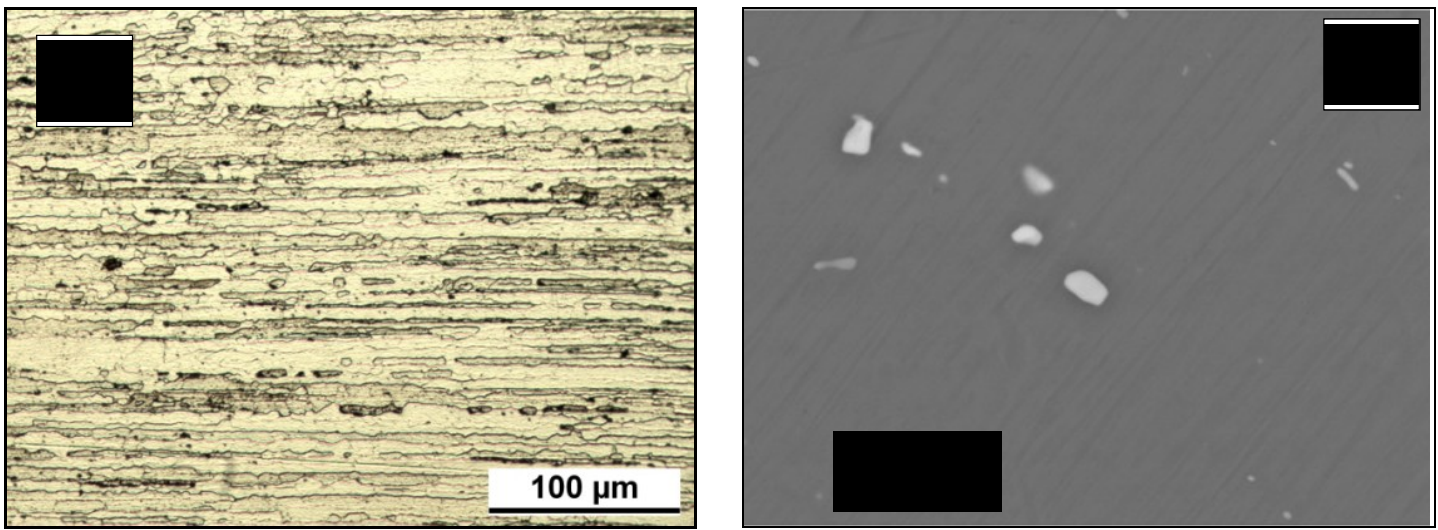

Fig. 1. $a$, $c$ : metallographic structure (OM) of the base materials; $b, d$ : second phases dispersed in the aluminium matrix (SEM, backscattered electrons).
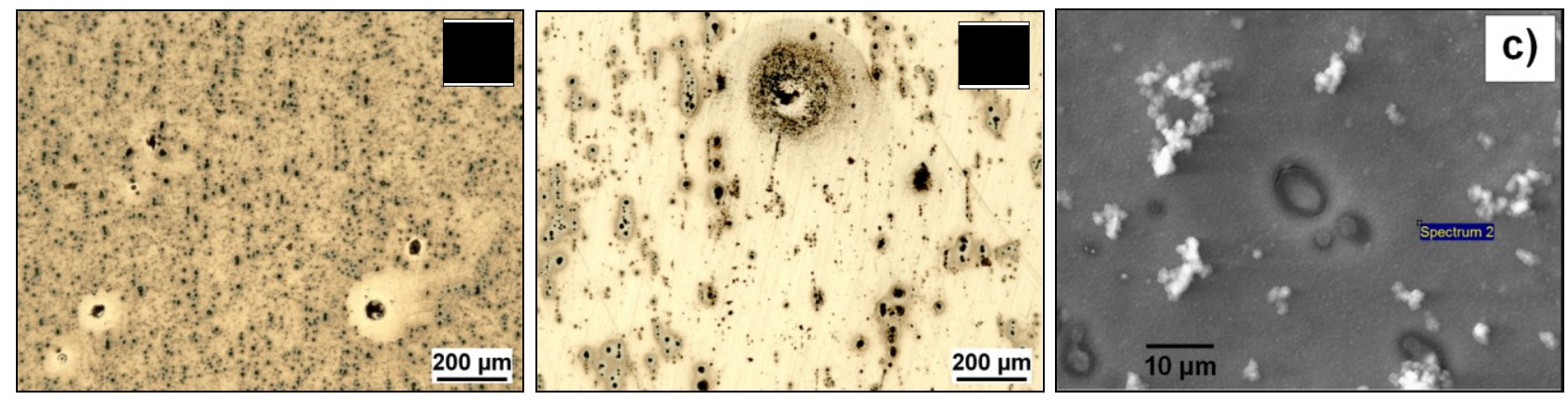

Fig. 2. Appearance (OM) of AA2139 (a) and AA2198 (b) surfaces after $4 \mathrm{~h}$ immersion in $0.6 \mathrm{M} \mathrm{NaCl}$ solution; $(c)$ appearance of the corrosion attack (SEM).

For the electrochemical tests, these specimens, with an electric copper wire contact fixed on the inner surface, were embedded in Epofix ${ }^{\circledR}$ resin, so that, after the preparation, they exposed the outer surface to the aggressive solutions. This surface was prepared by emery papers up to 1000 grade, washed with bi-distilled water, degreased with acetone and dried with hot air. 
The aggressive medium was $0.01 \mathrm{M} \mathrm{NaCl}$ (RPE Carlo Erba product) solution. The tested surfactants (Fluka products) were:

sodium salts of N-lauroylsarcosine (NLS) $\quad \mathrm{CH}_{3}\left(\mathrm{CH}_{2}\right)_{10} \mathbf{C O N}\left(\mathrm{CH}_{3}\right) \mathrm{CH}_{2} \mathrm{COONa}$;

N-lauroyl-N-methyltaurine (NLT)

dodecylbenzensulphonic acid (DBS)

and sodium lauryl sulphate (LS)

$\mathrm{CH}_{3}\left(\mathrm{CH}_{2}\right)_{10} \mathrm{CON}\left(\mathrm{CH}_{3}\right)\left(\mathrm{CH}_{2}\right)_{2} \mathrm{SO}_{3} \mathrm{Na}$;

$\mathrm{CH}_{3}\left(\mathrm{CH}_{2}\right)_{11} \mathrm{C}_{6} \mathrm{H}_{4} \mathrm{SO}_{3} \mathrm{Na}$;

$\mathrm{CH}_{3}\left(\mathrm{CH}_{2}\right)_{11} \mathrm{OSO}_{3} \mathrm{Na}$.

Electrochemical tests were performed in a $25( \pm 0.1){ }^{\circ} \mathrm{C}$ thermostated $250 \mathrm{ml}$ glass cell with a 3-electrode assembly: working electrode, reference electrode (saturated calomel electrode) and two symmetrical platinum wire counter-electrodes. These tests were carried out with a Princeton Applied Research PARSTAT 2263 Potentiostat-Galvanostat (PowerSUITE ${ }^{\circledR}$ software). The potentiodynamic polarization curves were recorded by applying a $0.2 \mathrm{mV} \mathrm{sec}{ }^{-1}$ scanning rate. The corrosion rate $\left(i_{\mathrm{CORR}}\right)$ values were obtained by cathodic Tafel line extrapolation to the corrosion potential $\left(E_{\mathrm{CORR}}\right)$ and percent Inhibition Efficiency (\%I.E.) was determined as:

$$
\% \text { I.E. }=\frac{i_{\text {CORR[BLANK }]}-i_{\text {CORR[INHIB.] }}}{i_{\text {CORR[BLANK }]}} \times 100
$$

To monitor the corrosion process, electrochemical impedance spectra were carried out on independent specimens in the $10^{5}-10^{-3} \mathrm{~Hz}$ frequency domain, applying a $10 \mathrm{mV} \mathrm{rms}$ sinusoidal perturbation at the corrosion potential. Owing to the low potential amplitude, each experiment lasting $168 \mathrm{~h}$ was carried out on the same electrode.

\section{Results}

In $0.01 \mathrm{M} \mathrm{NaCl}$ solution, the AA2139 corrosion process was initially defined by a cathodic polarization curve limited by oxygen diffusion $\left(i_{\mathrm{L}}\right.$ around $10 \mu \mathrm{A} \mathrm{cm} \mathrm{cm}^{-2}$ ) and an anodic polarization curve under pitting corrosion conditions (i.e. with a pitting potential, $E_{\mathrm{BR}}$, almost coincident with the corrosion potential, Fig. 3). The layer of spontaneous corrosion products (i.e. Al oxide-hydroxide) which develops and thickens during the time on the alloy surfaces particularly stifled the cathodic reaction of oxygen reduction, mainly at long immersion times. In fact, at $168 \mathrm{~h}$, the corrosion potential settled to more negative values (around $-0.7 \mathrm{~V}_{\mathrm{SCE}}$ ) and the cathodic polarization curve displayed a tafelian-like behaviour. At the same time, a well defined, although limited, passivity interval was being established, with $i_{\mathrm{PASS}}$ of few $\mu \mathrm{A} \mathrm{cm}^{-2}$, and a pitting potential of $-0.58 \mathrm{~V}_{\mathrm{SCE}}$. Beyond this last potential value, a sudden anodic current increase took place, owing to the pitting process begun by chloride anions, and the anodic current trend became similar to that of the initial polarization curves. 


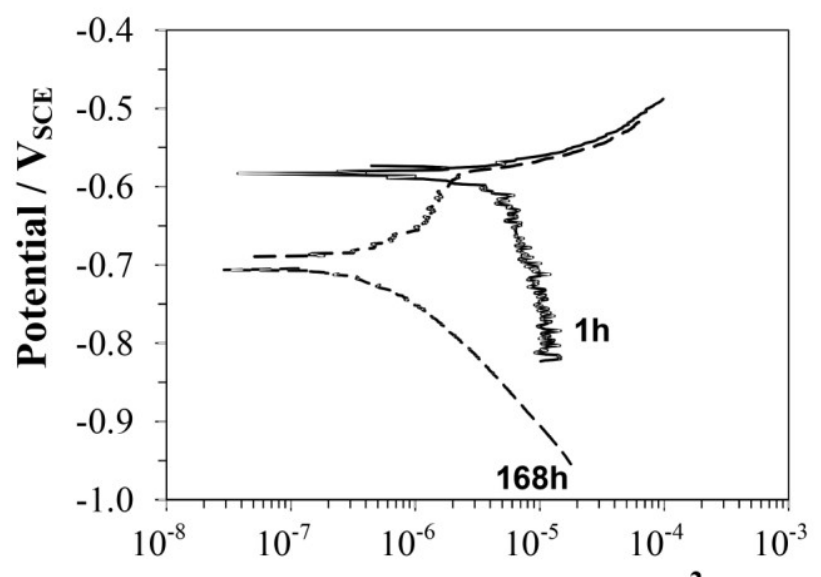

Current Density / A.cm ${ }^{-2}$

Fig. 3. Polarization curves of AA2139 at 1 and $168 \mathrm{~h}$ immersion time in $0.01 \mathrm{M} \mathrm{NaCl}$.
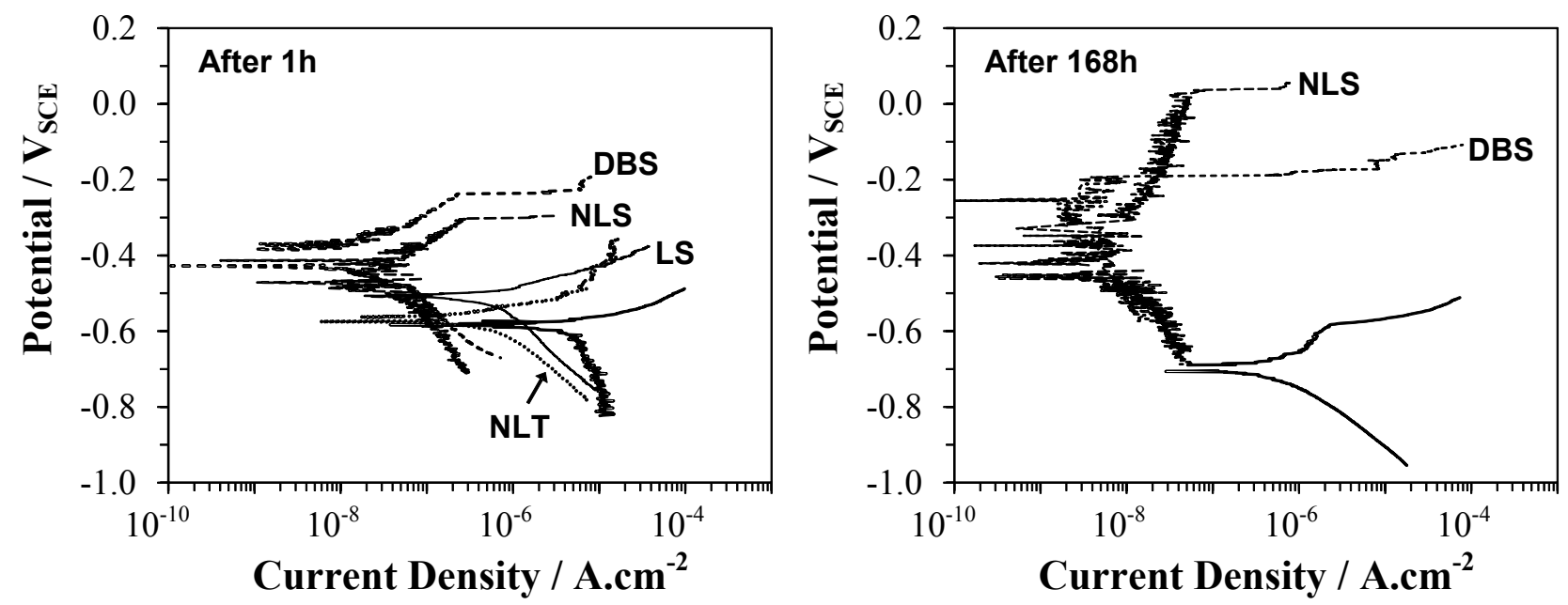

Fig. 4. Polarization curves of AA2139 after 1 (left) and $168 \mathrm{~h}$ (right) immersion in $0.01 \mathrm{M}$ $\mathrm{NaCl}$ in the presence of the various surfactants at $5 \times 10^{-3} \mathrm{M}$ concentration $\left(10^{-3} \mathrm{M}\right.$ for NLT).

Figures 4 show the polarization curves recorded after 1 and $168 \mathrm{~h}$ immersion in $0.01 \mathrm{M}$ $\mathrm{NaCl}$ solution in the presence of the various surfactants. NLT and LS exerted a limited inhibiting action on both the cathodic and anodic corrosion reactions, which lasted very few hours. On the contrary, the action promoted by DBS and NLS was much greater and was found to be more persistent.

After $1 \mathrm{~h}$ immersion the presence of $5 \times 10^{-3} \mathrm{M}$ NLS caused a net diminution in the cathodic and anodic polarization currents, the latter up to a pitting potential of $-0.3 \mathrm{~V}_{\mathrm{SCE}}$. Over time, the anodic reaction became more and more inhibited while the pitting potential moved to more positive values, so that after $168 \mathrm{~h}$ a net passivity domain was determined, characterized by an almost constant anodic current, $i_{\text {PASS }}$, lower than $0.1 \mu \mathrm{A} \mathrm{cm}{ }^{-2}$ and an $E_{\mathrm{BR}}$ attaining a value close to $+0.04 \mathrm{~V}_{\mathrm{SCE}}$ (Fig. 5). At the end of the test, the cathodic currents were reduced, in comparison to the blank, by about two orders of magnitude, 
while the reduction in the anodic currents was more noticeable, reaching around four orders of magnitude.

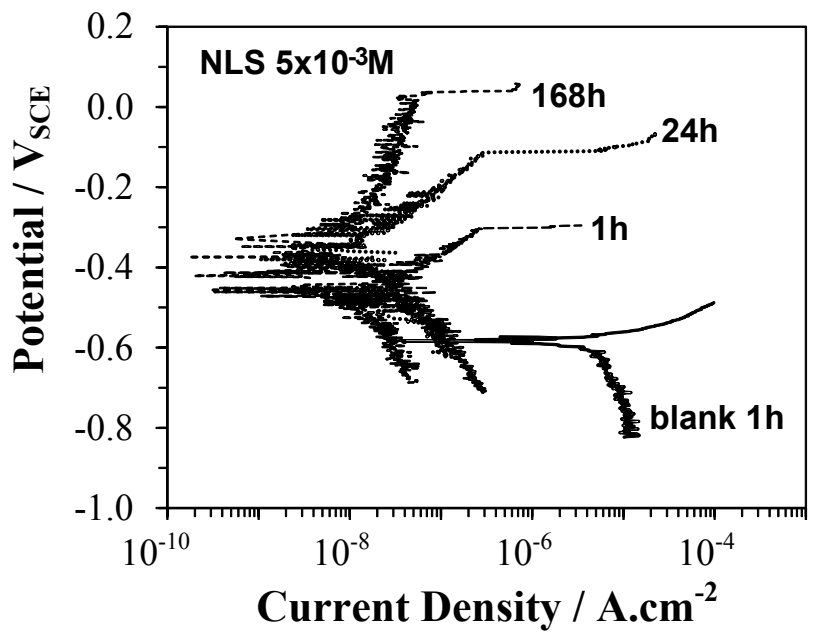

Fig. 5. Polarization curves of AA2139 at increasing immersion time in $0.01 \mathrm{M} \mathrm{NaCl}$ in the presence of $5 \times 10^{-3} \mathrm{M}$ NLS.
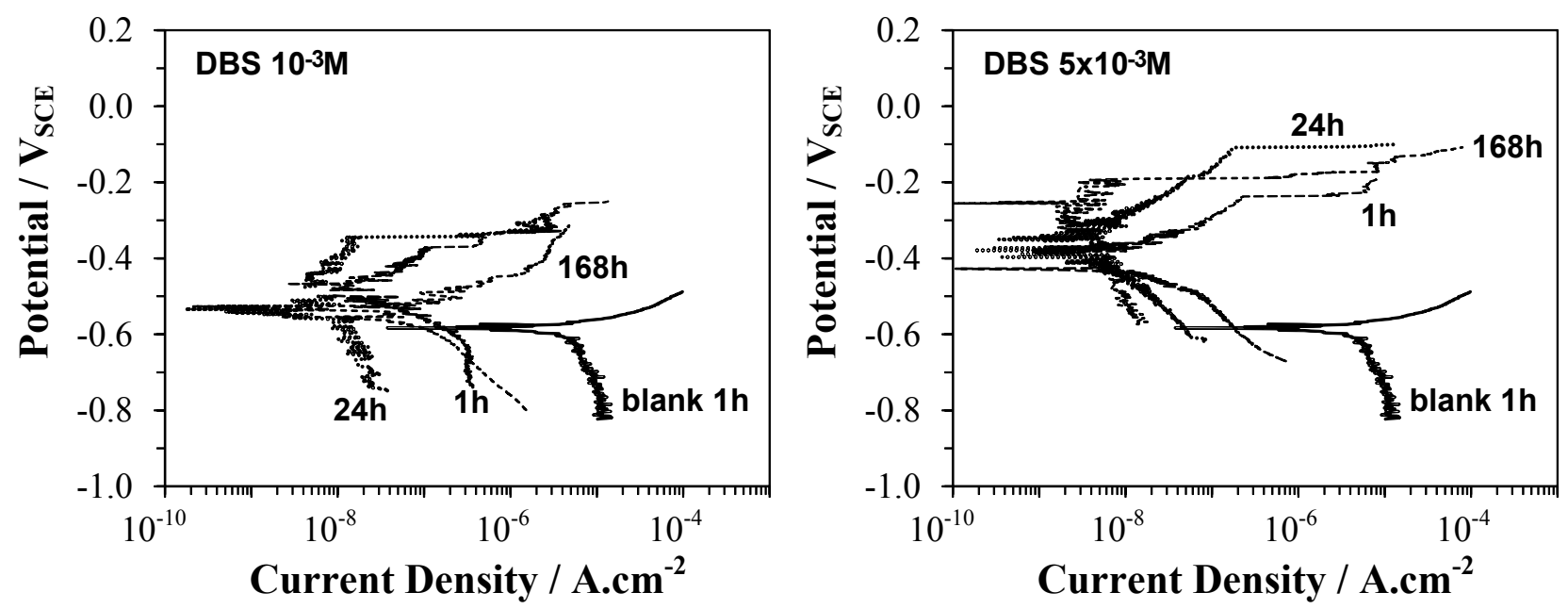

Fig. 6. Polarization curves of AA2139 at increasing immersion time in $0.01 \mathrm{M} \mathrm{NaCl}$ in the presence of $1 \times 10^{-3}$ (left) and $5 \times 10^{-3} \mathrm{M}$ (right) DBS.

Initially DBS at $10^{-3} \mathrm{M}$ concentration markedly decreased the currents of both the anodic and cathodic processes, an influence which had improved after $24 \mathrm{~h}$ testing, but not successively maintained (Fig. 6, left). Better and more lasting effects were obtained at $5 \times 10^{-3} \mathrm{M}$ concentration (Fig. 6, right). In this case, the cathodic and anodic polarization currents throughout the experiment were continuously reduced, while $E_{\mathrm{BR}}$ initially moved in the positive direction, reaching, at $24 \mathrm{~h},-0.11 \mathrm{~V}_{\mathrm{SCE}}$, and successively shifting to $-0.19 \mathrm{~V}_{\mathrm{SCE}}$ at $168 \mathrm{~h}$. Compared to NLS, at the end of the experiment (168 h), DBS presented about the same cathodic and anodic polarization curves, but a much less positive $\mathrm{E}_{\mathrm{BR}}$ value (Fig. 4, right). 

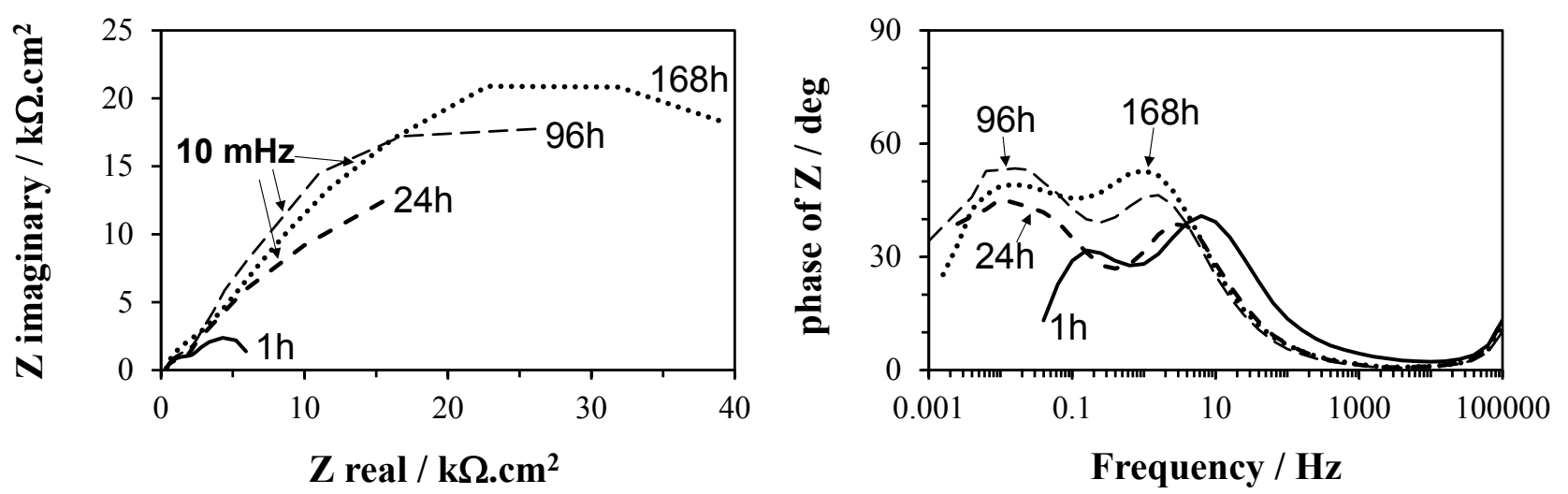

Fig. 7. Impedance spectra of AA2139 in $0.01 \mathrm{M} \mathrm{NaCl}$ solution.

In $0.01 \mathrm{M} \mathrm{NaCl}$ solution, Nyquist plots of AA2139 were characterized by two capacitive loops (Fig. 7), where the high frequency $(h f)$ one $\left(10^{1} \mathrm{~Hz}\right.$ characteristic frequency, $\left.f_{\mathrm{CHAR}}\right)$ was less wide than the low frequency $(l f)$ one $\left(10^{-1}-10^{-2} \mathrm{~Hz} f_{\mathrm{CHAR}}\right)$. Usually the former semicircle is assigned to the layer of aluminium oxide-hydroxide, while the latter is attributed to the corrosion process taking place mainly at the bottom of the defects of this passive layer [11,18-22]. Over time, the formation of a more and more protective corrosion product layer increased the low frequency impedance modulus $\left(|\mathrm{Z}|_{\mid \mathrm{ff}}\right)$ value, mainly by enlarging the size of the $l f$ capacitive loop. The size increase of the $h f$ and If loops can be attributed to the thickening of the natural protective oxide layer and the reduction in the layer porosity, respectively.

Similarly to AA2198, the spectra of AA 2139 recorded in the presence of the various surfactants at $5 \times 10^{-3} \mathrm{M}$ concentration showed a very large $|\mathrm{Z}|_{\text {If }}$ values just at the beginning $(1 \mathrm{~h})$ of the test (Figure 8). After $24 \mathrm{~h}$, due to the building of a more and more efficient inhibitor layer, the size of the capacitive loops had increased, chiefly due to the noticeable increase in the lf loop. While LS produced an increase in $|Z|_{\text {If }}$ of about one order of magnitude, NLS and DBS caused an increase of two orders of magnitude. However, at longer immersion times (168 h) only NLS and DBS maintained remarkable inhibiting effects.

Bode plots showed, after a certain time interval, two distinct time constants $\left(10^{2}-\right.$ $10^{3} \mathrm{~Hz}$ and $10^{-2} \mathrm{~Hz} f_{\mathrm{CHAR}}$ ), a sign of a certain, although limited, solution penetration as far as the metal surface. The former time constant could be characteristic of the surfactant's strengthened oxide layer and the latter of the corrosion process at the bottom of the pores. The initial marked extension of the $l f$ capacitive loop could be attributed to a very scarcely defective inhibitor layer (in comparison to the blank test), and its subsequent noticeable increase could indicate a decrease in the uncovered metal surface involved in the corrosive attack due to pore plugging by precipitation of insoluble Al salts of the surfactants.

Figures 9 compare the polarization curves of AA2139 and AA2198 in the chloride solution in the presence of $5 \times 10^{-3} \mathrm{M}$ NLS (left) or DBS (right). In the uninhibited solution, the cathodic polarization curves recorded on the two alloys displayed a very similar 
behaviour both from the beginning (when the cathodic reaction of oxygen reduction was characterized by a limiting current value) to the end of the testing interval (when the cathodic curve showed an almost tafelian behaviour) (Figure 9). On the contrary, the anodic polarization curves clearly differentiated, and that of AA2139 was always characterized by higher current densites, a less positive $\mathrm{E}_{\mathrm{BR}}$ value and a lower tendency to passivation than AA2198.
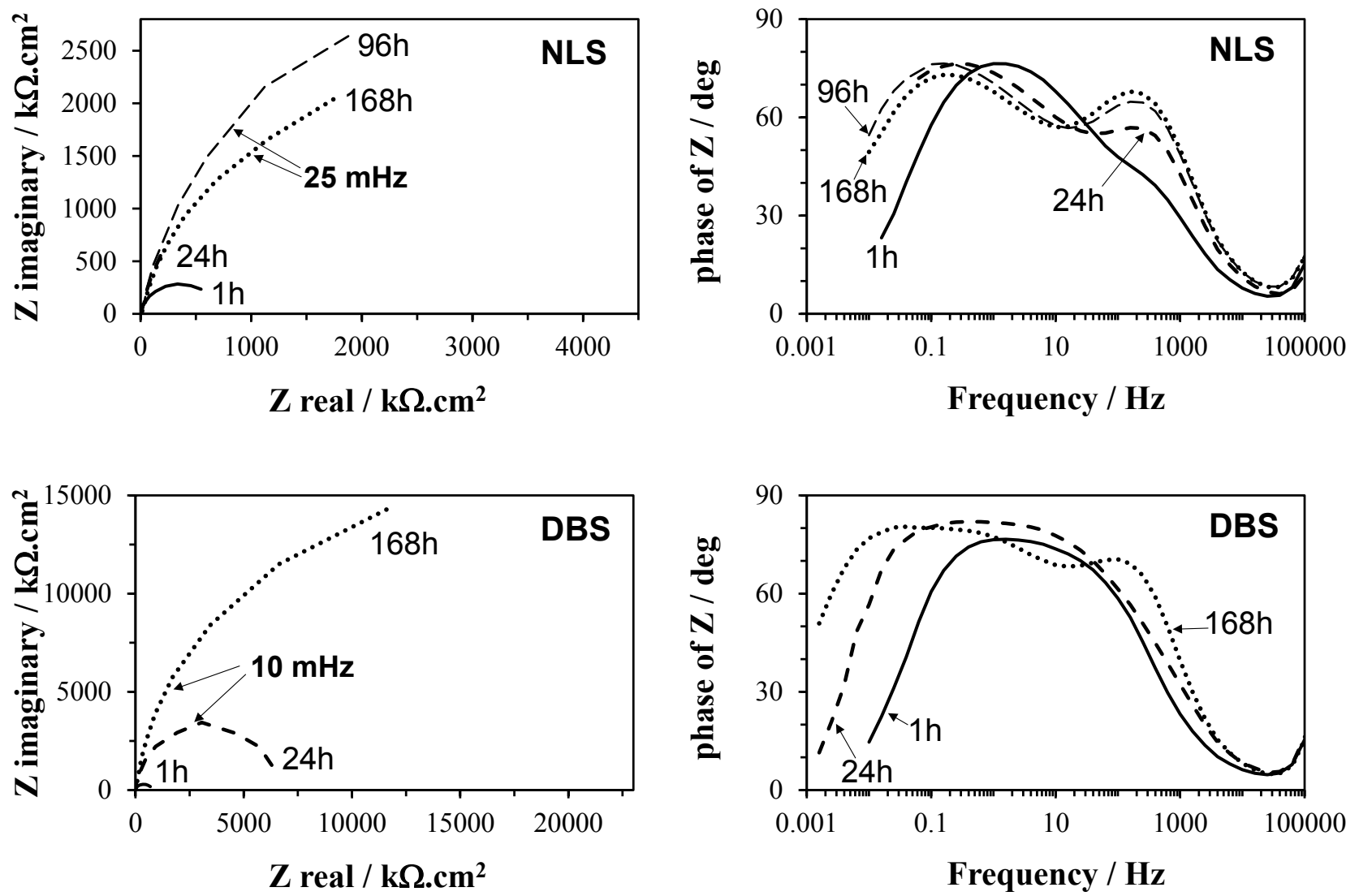

Fig. 8. Impedance spectra of AA2139 in $0.01 \mathrm{M} \mathrm{NaCl}$ solution inhibited by $5 \times 10^{-3} \mathrm{M} \mathrm{NLS}$ (above) or DBS (below).

The polarization curves recorded on AA2139 in the presence of a surfactant (either NLS or DBS) presented the same evolution determined on AA2198, i.e. a diminution chiefly in the anodic currents and a shifting of $\mathrm{E}_{\mathrm{BR}}$ towards more positive values over time. However, although the anodic polarization currents seemed to be similar, $E_{\mathrm{BR}}$ of AA2139 was more negative than that of AA2198 (Table 2). 

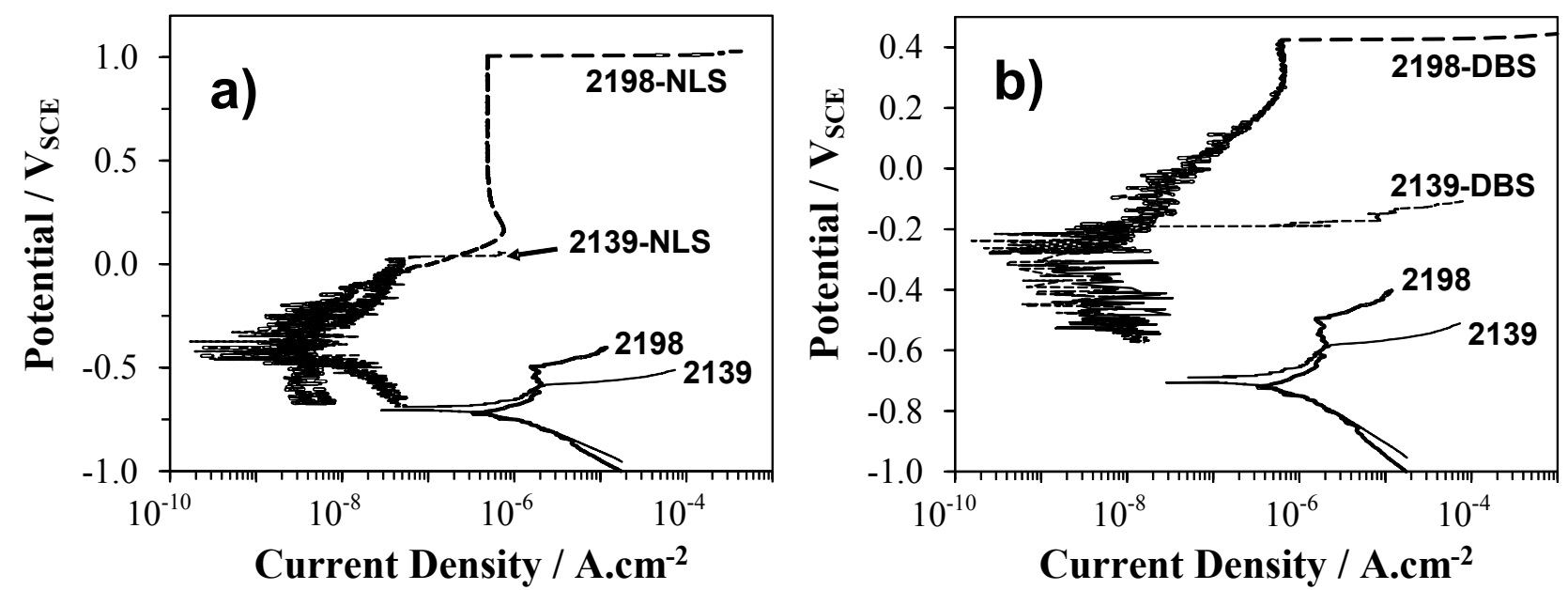

Fig. 9. Comparison between the polarization curves of AA2198 and AA2139 after $168 \mathrm{~h}$ in $0.01 \mathrm{M} \mathrm{NaCl}$ solution inhibited by $5 \times 10^{-3} \mathrm{M}$ NLS (a) or DBS (b).

Table 2 - Comparison of $\mathrm{E}_{\mathrm{BR}}$ values for the two alloys in $0.01 \mathrm{M} \mathrm{NaCl}$ in the presence of the surfactants at $5 \times 10^{-3} \mathrm{M}$ concentration. For comparison purposes, also the data of AA6351 [6] are reported.

\begin{tabular}{|c|c|c|c|c|c|c|c|}
\hline \multirow{3}{*}{$\begin{array}{l}\text { Surfactants } \\
\left(5 \times 10^{-3} \mathrm{M}\right)\end{array}$} & \multicolumn{7}{|c|}{$E_{\mathrm{BR}} / \mathrm{V}_{\mathrm{SCE}}$} \\
\hline & \multicolumn{3}{|c|}{ AA2139 } & \multicolumn{3}{|c|}{ AA2198 } & \multirow{2}{*}{$\begin{array}{c}\mathbf{A A 6 3 5 1} \\
1 \mathrm{~h}\end{array}$} \\
\hline & $1 \mathrm{~h}$ & $24 \mathrm{~h}$ & $168 \mathrm{~h}$ & $1 \mathrm{~h}$ & $24 \mathrm{~h}$ & $168 \mathrm{~h}$ & \\
\hline None & - & - & -0.580 & - & - & -0.470 & -0.620 \\
\hline NLS & -0.304 & -0.114 & +0.038 & +0.369 & +0.120 & +1.007 & -0.350 \\
\hline LS & - & - & - & -0.206 & +0.297 & +1.206 & -0.500 \\
\hline DBS & -0.239 & -0.111 & -0.192 & -0.120 & -0.083 & +0.426 & -0.530 \\
\hline
\end{tabular}

The $E_{\mathrm{BR}}$ (Table 2) and Inhibition Efficiency data determined from cathodic polarization curve extrapolation (\%I.E., Table 3) showed that the influence exerted on the two aluminium alloys by NLS and DBS was almost the same (i.e. a strong inhibition of the corrosion processes accompanied by a positive displacement of $E_{\mathrm{BR}}$ ), while that by LS was quite different: this surfactant exerted a negligible influence with regard to AA2139, as far as the corrosion inhibition and the pitting process were concerned, whereas its influence on AA2198 was much more evident. Similarly, the protective action of NLT towards AA2139 was minor and less durable than that exerted on AA2198, although, in both cases, the inhibitive effects decreased over time. In fact, at $1 \mathrm{~h}, \%$ I.E. for the former alloy it was $87 \%$ in comparison to $97 \%$ for the latter alloy; after $24 \mathrm{~h}$ NLT displayed a still acceptable \%I.E. value of $68 \%$ for AA2 198 . 
Table 3 - Comparison of \%I.E. values for the two alloys in $0.01 \mathrm{M} \mathrm{NaCl}$ in the presence of the surfactants at $10^{-3}$ and $5 \times 10^{-3} \mathrm{M}$ concentration. Blank $i_{\mathrm{CORR}}\left(\mu \mathrm{A} \mathrm{cm}{ }^{-2}\right)$ at 1,24 and $168 \mathrm{~h}: \mathrm{AA} 2139: 4.52 ; 1.40 ; 0.63$; AA2198: $1.69 ; 3.11 ; 0.78$.

\begin{tabular}{|c|c|c|c|c|c|c|c|c|c|c|c|c|}
\hline \multirow{4}{*}{ Surfactants } & \multicolumn{12}{|c|}{ \%I.E. } \\
\hline & \multicolumn{6}{|c|}{ AA2139 } & \multicolumn{6}{|c|}{ AA2198 } \\
\hline & \multicolumn{3}{|c|}{$10^{-3} \mathrm{M}$} & \multicolumn{3}{|c|}{$5 \times 10^{-3} \mathrm{M}$} & \multicolumn{3}{|c|}{$10^{-3} \mathrm{M}$} & \multicolumn{3}{|c|}{$5 \times 10^{-3} \mathrm{M}$} \\
\hline & $1 \mathrm{~h}$ & $24 \mathrm{~h}$ & $168 \mathrm{~h}$ & $1 \mathrm{~h}$ & $24 \mathrm{~h}$ & $168 \mathrm{~h}$ & $1 \mathrm{~h}$ & $24 \mathrm{~h}$ & $168 \mathrm{~h}$ & $1 \mathrm{~h}$ & $24 \mathrm{~h}$ & $168 \mathrm{~h}$ \\
\hline NLS & 3 & - & - & 98.9 & 98.6 & 98.5 & 83 & - & - & 98.0 & 99.86 & 99.59 \\
\hline NLT & 87 & Stim. & - & n.d. & n.d. & n.d. & 97.0 & 68 & - & n.d. & n.d. & n.d. \\
\hline LS & Stim. & Stim. & - & 87 & Stim & - & 72 & 90 & - & 94.2 & 99.63 & 99.05 \\
\hline DBS & 99.38 & 99.58 & 86 & 99.44 & 99.67 & 99.65 & 94.4 & 99.58 & 99.77 & 97.0 & 99.79 & 99.69 \\
\hline
\end{tabular}

*n.d. $=$ not determined

\section{Discussion}

The action of the anionic surfactants in stifling the corrosion and the pitting processes of aluminium alloys is attributable to their adsorption on the aluminium surface oxide layer through their polar (negatively charged) head groups so that in the end chloride anions become electrostatically repelled [6]. Moreover, van der Waals interactions through their long aliphatic chain allow the formation of a very compact, scarcely defective and, therefore, highly efficient layer which renders the metallic surface hydrophobic, thus hindering the attack of the electrolytic aqueous solutions.

On AA2139 too, anionic surfactants, chiefly NLS and DBS, improve the protective effects of the aluminium alloy natural passive film, as revealed by the markedly reduced polarization currents, wider passive interval and $E_{B R}$ positive shift. These substances contemporaneously decrease the passive layer porosity and this effect greatly improves over time by the easier pore plugging action due to the likely precipitation of an insoluble aluminium-surfactant salt in a layer with reduced porosity.

The highest efficiency of NLS can be attributed to a probable chemisorption effect due to its ability to form very stable 5-membered rings with metallic cations [23, 24]. For the lower polarizability of the sulphate and sulphonate groups in comparison to the carboxylate one, the other molecules are considered to be physisorbed and this accounts for their lower efficiency [6]. In this case, the higher effectiveness of DBS, in comparison to LS, supports the influence of $\pi$ electrons of the benzene ring in an adsorption stage.

The action of the surfactants is found to be related to the protective efficiency of the natural oxide layer developing on these alloys. On AA2139, where this passive layer is less protective than that formed on AA2198, the surfactants are less efficient. The action of LS and NLT on AA2139 is very limited both in time and extension, while, in general, the action carried out by DBS and NLS on AA2139 is alike to that previously found on the similar AA2198 alloy, but with a lower $\mathrm{E}_{\mathrm{BR}}$ positive shift. 
Regarding the inhibition of the pitting process, it is difficult to attribute the different behaviour between AA2198 and AA2139 to the alloy composition, because their composition is very similar (but Li content), or to the cathodic intermetallic composition. Since the corrosion attack is favoured in the $\mathrm{Cu}$-depleted zone adjacent the cathodic $\mathrm{Cu}$ and Fe-rich intermetallic precipitates, it is likely that the higher pit density in AA2139, in comparison to AA2198, is in relation to this behaviour: in the former alloy the intermetallic precipitate density is higher and the number of points of attack is higher than in AA2198, and this leads to a greater difficulty in withstanding the localized attack by these inhibiting substances.

\section{Conclusions}

1. Anionic surfactants can be efficient inhibitors of the pitting and corrosion process of AA 2139 in chloride media.

2. Since their inhibiting action is related to the surfactant adsorption on the natural aluminium oxide layer, NLS, which acts through chemisorption, is more effective than DBS, which acts through physical adsorption (even if supported by $\pi$ electrons of the benzene ring).

3. Moreover, surfactant action is affected by the efficiency of the aluminium passive layer; the passive layer of AA2198 is more protective than that of AA2139, therefore the surfactant action is, in general, superior on the former as compared to the latter alloy.

4. The influence on the pitting process can be linked to the density of the cathodic $\mathrm{Cu}$ - and Fe-rich intermetallic precipitates: the higher this density (e.g. AA2139), the more difficult it is to stifle the localized corrosion.

\section{References}

1. Z. Szklarska-Smialowska, Corros. Sci., 1999, 41, 1743.

2. S.-I. Pyun, S.-M. Moon, S.-H. Ahn and S.-S. Kim, Corros. Sci., 1999, 41, 653.

3. T. M. Salem, J. Horvath and P. S. Sidky, Corros. Sci., 1978, 18, 363.

4. M. Khobaib, L. Quakenbush and C. T. Lynch, Corrosion 1983, 39, 253.

5. Y. Isobe, S-I. Tanaka and F. Hine, Corros. Engineering (English translation), 1990, 39, no. 4, 185.

6. C. Monticelli, G. Brunoro, A. Frignani and F. Zucchi, Corros. Sci., 1991, 32, 693.

7. L. Garrigues, N. Pebere and F. Dabosi, Electrochim. Acta, 1996, 41, 1209.

8. A. A. El-Shafei, M. N. H. Moussa and A. A. El-Far, J. Appl. Electrochem., 1997, 27, 1075.

9. A. A. El-Shafei, S. A. Abd El-Maksoud and S. A. Fouda, Corros. Sci., 2004, 46, 579.

10. A. Yurt, G. Bereket and C. Ogretir, J. Molec. Struct., THEOCHEM, 2005, 725, 215.

11. G. Boisier, N. Portail and N. Pebere, Electrochim. Acta, 2010, 55, 6182.

12. S. Zor and H. Ozkazanc, Prot. Met. Phys. Chem. Surf., 2010, 46, 727.

13. R. Rosliza, W. B. Wan Nik and S. Izman, Adv. Mat. Res. 2011, 328-330, 1206. 
14. T. G. Harvey, S. G. Hardin, A. E. Hughes, T. H. Munster, P. A. White, T. A. Markley, P. A. Corrigan, J. Mandel, S. J. Garcia, J. M. C. Mol and A. M. Glenn, Corros. Sci., 2011, 53, 2184.

15. A. Balbo, A. Frignani, V. Grassi and F. Zucchi, accepted for the publication in Corros. Sci.

16. J. R. Galvele and S. M. De Micheli, Corros. Sci., 1970, 10, 795.

17. N. Birbilis and R. G. Buchheit, J. Electr. Soc., 2005, 152, no. 4, B140.

18. M. L. Zheludkevich, K. A. Yasakau, S. K. Poznyak and M. G. S. Ferreira, Corros. Sci., $2005,47,3368$.

19. A. K. Mishra and R. Balasubramaniam, Corros. Sci., 2007, 49, 1027.

20. N. C. Rosero-Navarro, M. Curioni, R. Bingham, A. Duran, M. Aparicio, R. A. Cottis and G. E. Thompson, Corros. Sci., 2010, 52, 3356.

21. I. A. Kartsonakis, A. C. Balaskas and G. C. Kordas, Corros. Sci., 2011, 53, 3771.

22. K. A. Yasakau, J. Tedim, M. L. Zheludkevich, R. Drumm, M. Shem, M. Wittmar, M. Veith and M. G. S. Ferreira, Corros. Sci., 2012, 58, 41.

23. A. Weisstuch, D. A. Carter and C. C. Nathan, Mater. Prot. \& Perform., 1971, 10, no. 4 , 11.

24. A. Weisstuch and K.R. Lange, Mater. Prot. \& Perform., 1971, 10, no. 12, 29. 